\title{
Overpressure Processing of Ag-sheathed Bi-2212 Tapes
}

\author{
J. L. Reeves, M. Polak, W. Zhang, E. E. Hellstrom, S. E. Babcock, and D. C. Larbalestier \\ Applied Superconductivity Center, University of Wisconsin-Madison, Madison, WI
}

N. Inoue and M. Okada

Hitachi Research Laboratory, Hitachi Ltd., Hitachi, Ibaraki, Japan

\begin{abstract}
A critical problem for melt-processed silversheathed $\mathrm{Bi}-2212$ tapes is gas release during heat treatment which deforms the sheath ("bubbling") and forms voids in the superconducting core. An overpressure furnace is used to study how the extent of bubbling changes with the total pressure $\left(\mathbf{P}_{\mathrm{tot}}\right)$. By processing in $\mathrm{P}_{\mathrm{tot}}$ up to 9 atmospheres with constant oxygen partial pressure $\left(\mathrm{pO}_{2}=1 \mathrm{~atm}\right)$, bubbling in coils is eliminated. The critical current density increases with increasing $P_{\text {tot. }}$ Also, the phase assemblage in overpressure-processed tapes is unchanged compared to conventionally processed tapes.
\end{abstract}

\section{INTRODUCTION}

When long lengths of $\mathrm{Bi}-2212$ tapes are processed in pure oxygen at 1 atmosphere (atm) pressure, the silver sheath deforms ("bubbles") at temperatures between $800-900^{\circ} \mathrm{C}$ [1]. The tape bubbles because the force from the gas pressure inside the tape is greater than the force from the $\mathrm{Ag}$ sheath and the external gas pressure. To prevent bubbling, the tapes could be processed in lower oxygen partial pressure $\left(\mathrm{pO}_{2}\right)$, but lower critical current densities $\left(\mathrm{J}_{\mathrm{c}}\right)$ result [2]. Another approach was taken by researchers at Hitachi who developed a "gas pressure melting" method that utilized total pressure $\left(\mathrm{P}_{\mathrm{tot}}\right)$ and $\mathrm{pO}_{2}$ greater than 1 atm during processing of $\mathrm{Bi}-2212$ wires [3]. They found that increasing $P_{\text {tot }}$ resulted in a more homogeneous distribution of small $(<0.6 \mathrm{~mm})$ voids in the core.

In our overpressure approach, we use a mixture of $\mathrm{O}_{2}$ and an inert gas (Ar) with $\mathrm{P}_{\text {tot }}>1$ atm and fixed $\mathrm{pO}_{2}=1$ atm. Since $\mathrm{O}_{2}$ diffuses rapidly through the $\mathrm{Ag}$, the $\mathrm{pO}_{2}$ inside and outside the tape quickly equilibrates. In contrast, Ar does not equilibrate during the short time at high temperature. Thus, Ar supplies the external pressure to balance the gas pressure inside the tape. The $J_{c}$ and microstructure of these overpressure-processed tapes are compared to conventionally processed tapes.

\section{EXPERIMENTAL CONDITIONS}

The Bi-2212 tapes with powder composition Bi:Sr:Ca:Cu = 2.1:2:1:1.95 were made using the OPIT process and had a final thickness of $140 \mu \mathrm{m}$. To ascertain the role of carbon in bubble formation, two tapes with different carbon content

Manuseript received August 27, 1996.

This work was supported in part by the Advanced Research Projects Agency (N00014-90-J-4115) and Electric Power Research Institute (RP8065-6). were made. The initial carbon content of the powder was 710 ppmwt (parts per million by weight) as measured by hightemperature combustion infrared detection. To lower the carbon content to 220 ppmwt, powder was heated to $700^{\circ} \mathrm{C}$ in partial vacuum with flowing $\mathrm{O}_{2}$ for 1 day. Coils were made by sealing the ends of $30 \mathrm{~cm}$ of tape and winding the tape around a $3.2 \mathrm{~cm}$ diameter $\mathrm{MgO}$ coated Inconel mandrel. The two coils with 710 and 220 ppmwt carbon were heated at $5^{\circ} \mathrm{C} / \mathrm{min}$ to $900^{\circ} \mathrm{C}$ in pure $\mathrm{O}_{2}$ with $\mathrm{P}_{\text {tot }}=1$ atm, held at $900^{\circ} \mathrm{C}$ for 15 minutes, and then furnace cooled. This process was repeated for $P_{\text {tot }}=2,4.6,6,8$, and 9 atm to see what effect $P_{\text {tot }}$ had on bubbling in low and high carbon content tapes. The gas pressure was established in the furnace before heating and was maintained until cooling to room temperature. For $\mathrm{P}_{\mathrm{tot}}>1$ atm, an $\mathrm{O}_{2} / \mathrm{Ar}$ gas mixture was used to maintain a fixed $\mathrm{pO}_{2}=$ $1 \mathrm{~atm}$.

For the electromagnetic and microstructural characterization of fully processed tapes, short lengths (4-8 $\mathrm{cm}$ ) of 162 ppmwt $C$ tape with sealed ends were melt processed in the overpressure furnace using the heating schedule shown in Fig. 1.

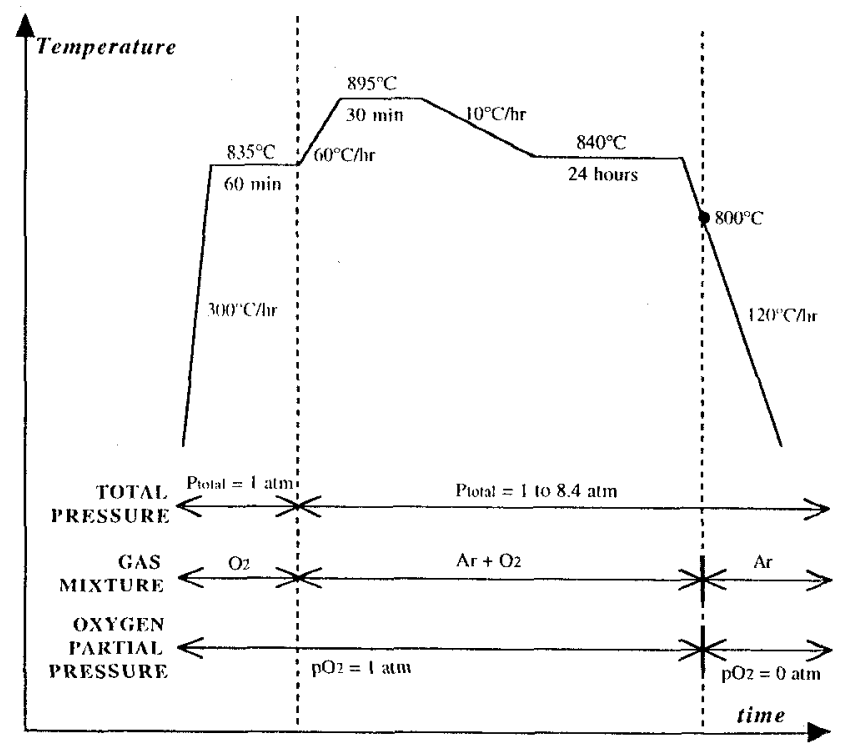

Fig. 1. Heat treatment for $\mathrm{Bi}-2212$ tapes processed in the overpressure furnace. The final cooling rate of $120^{\circ} \mathrm{C} / \mathrm{hr}$ is the fastest rate possible with this furnace design. 
The cooling rate of $120^{\circ} \mathrm{C} / \mathrm{hr}$ during the last step of the heat treatment is the fastest cooling rate we can achieve with our overpressure furnace. In order to see what effect a faster cooling rate has on $J_{c}$, one set of samples was processed at $\mathrm{P}_{\mathrm{tot}}=\mathrm{pO}_{2}=1 \mathrm{~atm}$ using an identical heat treatment schedule in a different furnace that is capable of cooling much more quickly $\left(700^{\circ} \mathrm{C} / \mathrm{hr}\right)$. The transport critical current was measured with multiple voltage taps over $3 \mathrm{~cm}$ sections using the standard four point probe technique at $0 \mathrm{~T}, 4.2 \mathrm{~K}$, with a $1 \mu \mathrm{V} / \mathrm{cm}$ criterion. Backscattered electron imaging was done on the JEOL JEM6100 scanning electron microscope (SEM) using energy dispersive $x$-ray spectroscopy (EDS) for phase identification.

\section{RESULTS AND DISCUSSION}

\section{A. Effect of overpressure on bubbling}

To illustrate the effect of carbon content and $P_{\text {tot }}$ on bubble formation, the length and thickness of the individual bubbles that formed at a lower pressure (2 atm) and a higher pressure $(8 \mathrm{~atm})$ were measured. Fig. 2 shows that with increasing $P_{t o t}$, the calculated volume and number of bubbles decreases for both high and low carbon content tapes. Also, at both 2 atm and $8 \mathrm{~atm}$, the high carbon content tape had more bubbles than the low carbon content tape.

The percentage of the tape length that bubbled is plotted versus $P_{\text {tot }}$ in Fig. 3. In pure oxygen where $P_{t x}=\mathrm{pO}_{2}=1 \mathrm{~atm}$, the entire coil bubbles. Even $1 \mathrm{~atm}$ of overpressure $\left(\mathrm{P}_{\mathrm{tor}}=2\right.$ $\mathrm{atm})$ significantly reduces bubbling. The percentage of tape length that bubbles continues to slowly decrease as the overpressure increases. The $P_{t a t}$ needed to eliminate bubbling increases with increasing carbon content. $P_{\text {tot }}=8 \mathrm{~atm}$ and $P_{\text {tot }}$ $=9 \mathrm{~atm}$ eliminates bubbling in the lower and higher carbon content tapes respectively. This result is not surprising, as our previous work has implicated $\mathrm{CO}_{2}$ as the bubble forming gas [4].

Applying a large enough overpressure during heating to the melting temperature stops bubbling. However, the trapped gas causes further problems. The consequences of having gas still trapped inside the core were seen during the initial investigation we did at Hitachi of the effect of overpressure during the entire heat treatment. One meter of tape with 500 ppmwt $\mathrm{C}$ was wrapped into a $3.2 \mathrm{~cm}$ diameter coil and processed in the Hitachi overpressure system with the following heat treatment at $\mathrm{P}_{\mathrm{tot}}=6 \mathrm{~atm}$ and $\mathrm{pO}_{2}=1 \mathrm{~atm}$ : vacuum anneal at $740^{\circ} \mathrm{C}$ for 16 hours, heat to $890^{\circ} \mathrm{C}$ at $5^{\circ} \mathrm{C} / \mathrm{min}$, hold at $890^{\circ} \mathrm{C}$ for 30 minutes, cool at $10^{\circ} \mathrm{C} / \mathrm{hr}$ to $840^{\circ} \mathrm{C}$, hold at $840^{\circ} \mathrm{C}$ for 24 hours, and furnace cool to room temperature. The silver sheath did not bubble; however, $\mathrm{J}_{\mathrm{c}}$ was low. The microstructure of this tape showed large voids in the core. Therefore, even when the outside of the $\mathrm{Ag}$ sheath does not bubble, large voids are still present inside the

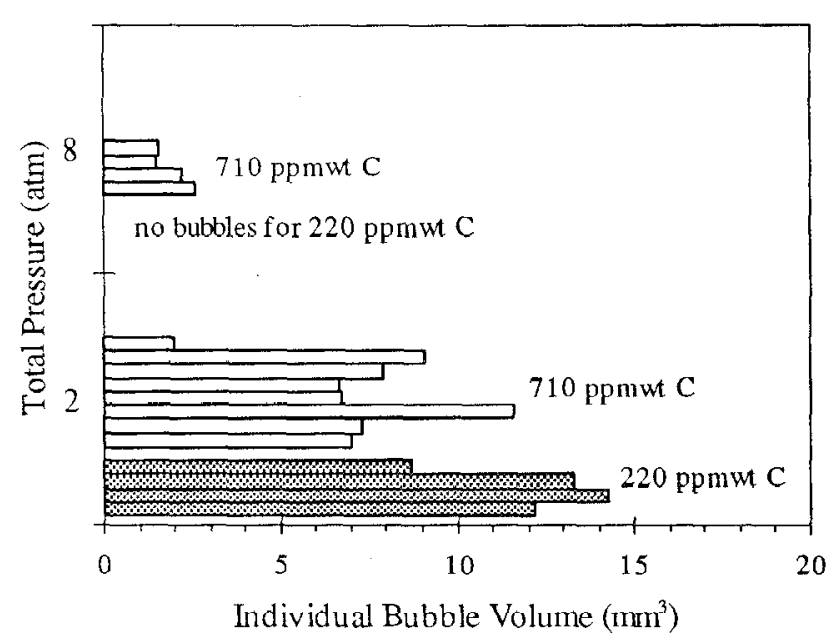

Fig. 2. Histogram of volume and number of bubbles for $\mathrm{P}_{\mathrm{tot}}=2$ and $8 \mathrm{~atm}, \mathrm{pO}_{2}$ $=1 \mathrm{~atm}$. At each pressure, more bubbles formed in the high carbon content tape. Additionally, for each carbon content, increasing the pressure decreased the size and number of bubbles that formed.

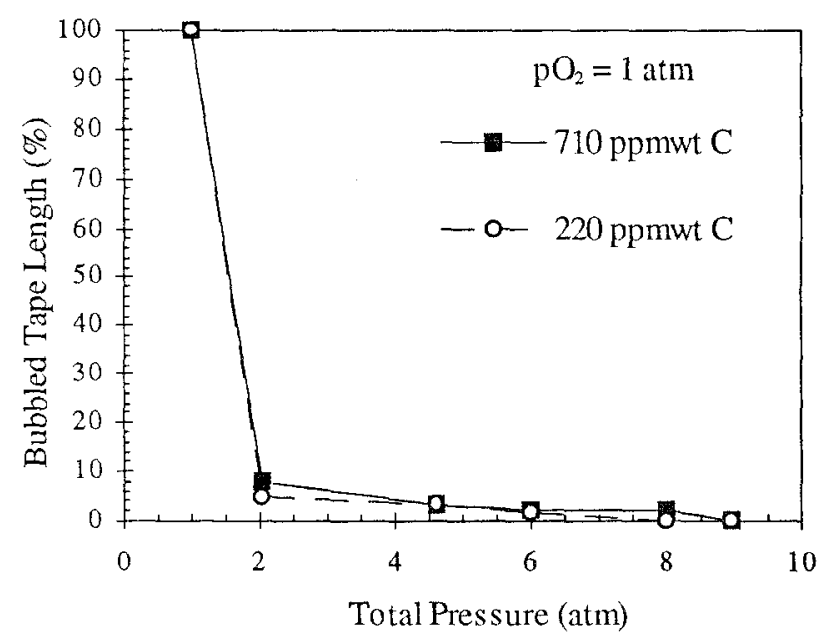

Fig. 3. Graph of percentage of bubbled tape length vs. total pressure. Having just $1 \mathrm{~atm}$ of overpressure $\left(\mathrm{P}_{\text {tot }}=2 \mathrm{~atm}\right)$ significantly reduces bubbling; bubbling is eliminated by $P_{t o t}=9$ atm for even the highest carbon content tape.

core. These voids degrade the electromagnetic properties of the superconductor. Therefore, in later experiments, low carbon content tape was used in conjunction with overpressure processing in order to minimize bubbling and increase $\mathrm{J}_{c}$.

\section{B. Effect of overpressure on $J_{\circ}$}

Fig. 4 shows that increasing $P_{\text {tot }}$ from $1 \mathrm{~atm}$ to $8.1 \mathrm{~atm}$ with $\mathrm{pO}_{2}=1 \mathrm{~atm}$ results in the substantial increase in $\mathrm{J}_{\mathrm{c}}$ for the slow cooled $\left(120^{\circ} \mathrm{C} / \mathrm{hr}\right)$ tapes. Also, there is less scatter in 


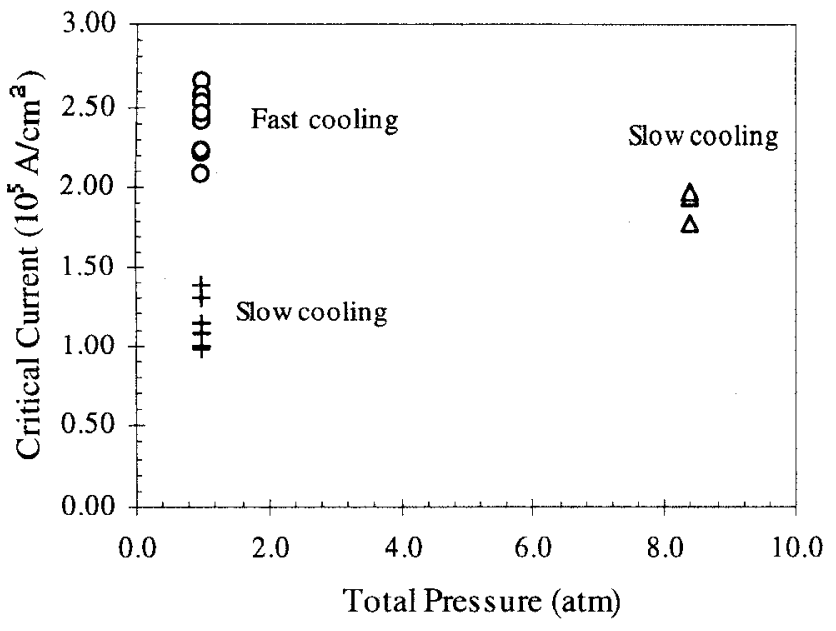

Fig. 4. $\mathrm{J}_{\mathrm{c}}$ vs. pressure with fixed $\mathrm{pO}_{2}=1 \mathrm{~atm}$. The fast $\left(700^{\circ} \mathrm{C} / \mathrm{hr}\right.$ in $\left.\mathrm{O}_{2}\right)$ and slow $\left(120^{\circ} \mathrm{C} / \mathrm{hr}\right.$ in $\left.\mathrm{Ar}\right)$ cooling rates refer to the last step in the heat treatment shown in Fig. 1. For the slow cooled samples, increasing pressure increases $\mathrm{J}_{\mathrm{c}}$. However, the highest $\mathrm{J}_{\mathrm{c}}$ samples are fast cooled.

the $\mathrm{J}_{\mathrm{c}}$ values at $8.1 \mathrm{~atm}$ than at $1 \mathrm{~atm}$. The overpressure compresses the core during processing, and may encourage Bi-2212 grain alignment, reduce porosity, and thus improve the $\mathbf{J}_{\mathrm{c}}$ of the superconductor. If this is indeed the case, overpressure-processed tapes should carry more current than conventionally processed tapes. The data show that the cooling rate has a significant effect on $\mathrm{J}_{\mathrm{c}}$; fast cooling in $\mathrm{pO}_{2}$ $=1 \mathrm{~atm}$ is needed to achieve high $\mathrm{J}_{\mathrm{c}}$. Therefore, incorporating fast cooling into the overpressure processing should improve $\mathrm{J}_{\mathrm{c}}$. However, fast cooling is not feasible for coils that have a large thermal mass, and modifications in the cooling process need to be developed that allow slow cooling while retaining high $\mathrm{J}_{\mathrm{c}}$.

\section{Effect of overpressure on microstructure}

Fig. 5 shows a representative backscattered electron image of a sample processed in the overpressure furnace with $\mathrm{P}_{\mathrm{tot}}=$ $8.1 \mathrm{~atm}, \mathrm{pO}_{2}=1 \mathrm{~atm}$, and furnace cooling $=120^{\circ} \mathrm{C} / \mathrm{hr}$. The microstructure contains the expected phase assemblage for processing in $\mathrm{pO}_{2}=1$ atm: $\mathrm{Bi}-2212$, small grains of $(\mathrm{Sr}, \mathrm{Ca})_{14} \mathrm{Cu}_{24} \mathrm{O}_{x} \quad(14: 24$ AEC (alkaline earth cuprate)) particles, and very few small grains of $\mathrm{Bi}_{2}(\mathrm{Sr}, \mathrm{Ca})_{4} \mathrm{O}_{x}(2: 4 \mathrm{CF}$ $(\mathrm{Cu}$ free)) particles. Also present are thin long grains of $\mathrm{Bi}_{2} \mathrm{Sr}_{2} \mathrm{CuO}_{x}$ (2201) from the liquid that transformed to 2201 on cooling from $840^{\circ} \mathrm{C}$ to room temperature and possibly from 2212 that decomposed during cooling. The same phase assemblage is seen in tapes processed at $\mathrm{P}_{\text {tot }}=\mathrm{pO}_{2}=1 \mathrm{~atm}$ and furnace cooling $=120^{\circ} \mathrm{C} / \mathrm{hr}$, but there is a large amount of 2201 in this tape(Fig. 6).

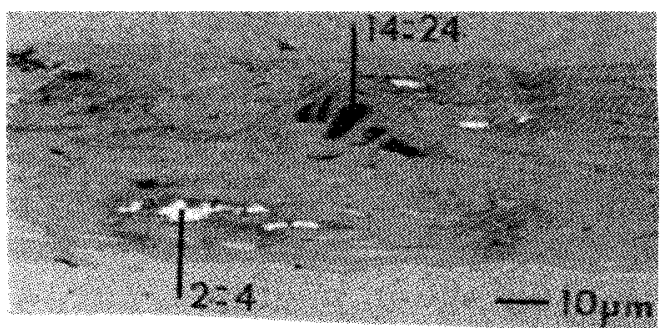

Fig 5. Backscattered electron image of overpressure-processed tape with furnace cooling $=120^{\circ} \mathrm{C} / \mathrm{hr}, \mathrm{P}_{\mathrm{tot}}=8.1 \mathrm{~atm}, \mathrm{pO}_{2}=1 \mathrm{~atm}$. The nonsuperconducting phase particles include 14:24 AEC and 2:4 CF.

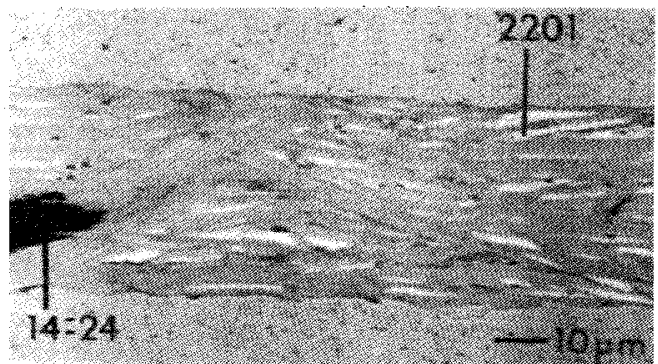

Fig 6. Backscattered electron image of overpressure-processed tape with furnace cooling $=120^{\circ} \mathrm{C} / \mathrm{hr}, \mathrm{P}_{\mathrm{tot}}=1 \mathrm{~atm}, \mathrm{pO}_{2}=1 \mathrm{~atm}$. The nonsuperconducting phase particles include 14:24 AEC and Bi-2201.

\section{SUMMARY}

While bubbling is still dependent on the starting carbon content of the $\mathrm{Bi}-2212$ powder, overpressure processing, defined as the application of inert gas pressure above the equilibrated $\mathrm{pO}_{2}$, can eliminate visible bubbling of the silver sheath. Although overpressure processing results in higher $\mathrm{J}_{\mathrm{c}}$ than conventional processing, the final cooling rate also has a strong effect on the current-carrying capability of the tapes. The results suggest that while overpressure processing may decrease porosity in the core and encourage grain alignment, slow cooling rates may cause the $\mathrm{Bi}-2212$ to decompose, thus degrading the current paths and decreasing the $J_{c}$. Either incorporating fast cooling or modifying the slow cooling process may result in even higher $\mathrm{J}_{\mathrm{c}}$.

\section{REFERENCES}

[1] E. Hellstrom and W. Zhang, "Formation and prevention of bubbles when melt processing $\mathrm{Ag}$-sheathed $\mathrm{Bi}_{2} \mathrm{Sr}_{2} \mathrm{CaCu}_{2} \mathrm{O}_{x}$ (2212) conductors," Supercond. Sci. Technol., vol. 8, pp. 317-323, May 1995.

[2] A. Endo and S. Nishikida, "Effects of heating temperature and atmosphere on critical current density of $\mathrm{Bi}_{2} \mathrm{Sr}_{2} \mathrm{Ca}_{1} \mathrm{Cu}_{2} \mathrm{Ag}_{0.8} \mathrm{O}_{\mathrm{y}} \mathrm{Ag}-$ sheathed tapes," IEEE Trans. Appl. Supercond, vol. 3, pp. 931-934, March 1993.

[3] T. Kanai and N. Inoue, "Development of gas pressure melting (GPM) method for Ag-sheathed Bi-2212," J. Mat Sci., vol. 30, pp. 3200-3206, June 1995.

[4] W. Zhang and E. E. Hellstrom, Physica $C$, "The influence of carbon on melt processing $\mathrm{Ag}$-sheathed $\mathrm{Bi}_{2} \mathrm{Sr}_{2} \mathrm{CaCu}_{2} \mathrm{O}_{x}$ Tape," vol. 234, pp. 137145,1994 